\title{
Comparison of Crown-Root Relationships of Maxillary Central Incisors in Various Malocclusions
}

\author{
Rajwinder Singh Brar ${ }^{1} \quad$ Mandeep Bhullar ${ }^{1} \quad$ Sanjay Mittal ${ }^{1} \quad$ Divya Singla $^{1} \quad$ Isha Aggarwal ${ }^{1}$ \\ ${ }^{1}$ Department of Orthodontics and Dentofacial Orthopedics, Bhojia \\ Dental College and Hospital, Baddi, Himachal Pradesh, India

\begin{abstract}
Address for correspondence Rajwinder Singh Brar, Department of Orthodontics and Dentofacial Orthopedics, Bhojia Dental College and Hospital, Baddi 173205, Himachal Pradesh, India (e-mail: brartaurian@yahoo.com).
\end{abstract}

Dent J Adv Stud 2019;7:28-34

\begin{abstract}
Keywords

- crown-root angle

- class II div 1 malocclusion

- class II div 2 malocclusion

- labial crown-root angle
\end{abstract}

\section{Introduction}

Variability in tooth morphology is a crucial thought within the attainment of an ideal occlusion of teeth. Maxillary central incisors are the greatest noticeable teeth. ${ }^{1}$ Typically, even slight misplacement of these incisors is of great deal to the patient. Additionally, very poor positioning of the incisors can affect the facial profile and affects the lip closure. Discrepancies in physical outline of the maxillary central incisors affect the treatment or the posttreatment phase of orthodontic therapy. Crown-root angle is one of the important features comprising the morphology of central incisors.

In cephalometric systems, the longitudinal axis of either of the upper central incisors is recorded daily as the axis is demarcated by Bjork, ${ }^{2}$ which is the line passing through the point incision superius, that is, midpoint of the cutting edge of the more protruding the upper central tooth and apex. $^{2}$ However, it is repeatedly seen that when the long axis of the root is drawn distinctly from the long axis of the crown, it is often noted that these two axes do not coincide. The longitudinal axis of the crown of a tooth can vary considerably from that of the root. The corresponding angle between these two longitudinal axes is defined as the crown to root angle and was named the collum angle by Andreasen in $1930 .^{3}$ The collum angle, therefore, is the supplementary angle of the crown to root angulation, used to correlate the angular difference between the two axes. Conferring to Taylor, root-crown relation varies greatly because they are subject to dissimilarities in curvature. In different words, when one sees the central incisor from the proximal, as on a cephalometric radiogram, a line drawn from the root apex to incision superius may not pass through the center of the tooth at the cementoenamel junction (CEJ). ${ }^{4}$ The crown could
C2019 Bhojia Dental College and Hospital affiliated to Himachal Pradesh University

License terms

$10.1055 / \mathrm{s}-0039-1685129$

ISSN 2321-1482.
November 26, 2018
accepted after revision

February 7, 2019

published online

April 4, 2019 
show "bent" to the lingual or labial, in reference to the root. During a study by Delivanis and Kuftinec, it was seen that in class II division (div) 2 patients, the crowns of the maxillary central incisors bear to be "bent" to the lingual very often than in patients with different types of malocclusion. ${ }^{5}$ This trend has long been well known by orthodontists and was even suggested by Backlund to be a causative factor in the progress of class II div 2 malocclusions. ${ }^{6}$ During a study of extracted maxillary central incisors, Carlsson and Rönnerman found the angle between the crown and root axes to vary by as much as 13 degrees. ${ }^{7}$ It has been anticipated by Delivanis and Kuftinec that the crown-root angulation labeled as occurring in class II div 2 malocclusions may impede orthodontic intrusion and torque of the incisors and, in serious cases, may rise the hazard of perforating the palatal cortical plate. They also recommend that the long axis of the crown alone, and not the complete tooth, be used in analyses, specifically in class II, div 2 cases. $^{5}$

The tradition of current orthodontics is broadly grounded on the usage of the straight wire edgewise appliance initially described by Andrews and Schirmer in $1968 .^{8}$ The arrival of this approach has permitted the orthodontist to proceed more resourcefully by inserting less bends in wires, mainly at the finishing steps of treatment, with further expected results. The drawbacks of the straight-wire appliance become probable, however, once one acknowledges the inconsistency built in natural crown forms, as well as the unpredictability of root location in relationship to the clinical crown. The technique is based on the supposition that root angulation to the crown is 0 degree.

This becomes important where torquing of the crowns may affect root position. In severe cases, the root may inadvertently encroach the labial or lingual cortical plates, causing unwarranted root resorption and dehiscence. In addition, aberrant crown to root angulations may confound intended axial loading when attempting to intrude or extrude teeth. ${ }^{9}$ Thus, the angle formed by the anatomical axes of the crown and root may have a noteworthy impact in the treatment in orthodontics. Sometimes, it is difficult to calculate the collum angle by the technique proposed by Andreasen. Another method to describe the crown and root axes has been proposed by Bauer. It is called labial crown-root angle. ${ }^{10}$

\section{Aims and Objectives}

The aim of this study is to compare the crown-root and labial crown-root angles in class I, class II div 1, and class II div 2 malocclusion, and to find a correlation between crown-root and labial crown-root angles.

- To measure and compare crown-root and labial crownroot angles in patients with class I and class II div 1 malocclusions.

- To measure and compare crown-root and labial crownroot angles in patients with class I and class II div 2 malocclusions.

- To measure and compare crown-root and labial crownroot angles in patients with class II div 1 and class II div 2 malocclusions.

- To find a correlation between crown-root and labial crown-root angles.

\section{Materials and Methods}

This research was planned as a cross-sectional cephalometric study to measure the crown-root and labial crown-root angles of maxillary central incisors on cephalogram of patients with class I, class II div 1, and class II div 2 malocclusions. Samples were collected from the patient reporting to the Department of Orthodontics and Dentofacial Orthopedics Bhojia Dental College, Baddi, Himachal Pradesh.

Three groups were formed on the base of skeletal and dental malocclusions. A sample of 45 patients ( 23 females and 22 males) with age range from 11 to 27 years and mean age of 17 years was taken. The sample was divided into class I, class II div 2, and class II div 1 malocclusions with 15 patients in each group (-Table $\mathbf{1}$ ).

All lateral cephalographs were taken by the operator with patients standing with Frankfort horizontal plane parallel to the floor, the sagittal plane perpendicular to the X-ray beam, and the teeth in centric occlusion. All radiographs were taken using the cephalostat from Advapex Panoramic Systems (Apex Medical Systems Pvt. Ltd., New Delhi, India). The exposure of the X-ray source was $65 \mathrm{kV}$ and 16 Ma for 1.2 seconds. The equipment had a fixed film to focus plane distance of $190 \mathrm{~cm}$ and a fixed film to midsagittal plane distance of $10 \mathrm{~cm}$ with a final amplification of $10 \%$. For all patients $8-\times 10$-in $(20.32$ $\times 25.4 \mathrm{~cm}$ ) films were used, and cephalogram tracings were done on acetate sheet.

- Inclusion criteria for class I malocclusion: Skeletal class I, dental class I, proper image quality, and clarity of cephalograms.

- Inclusion criteria for class II div 1 malocclusion: Skeletal class II, dental class II div 1, proper image quality, and clarity of cephalograms.

- Inclusion criteria for class II div 2 malocclusion: Skeletal class II, dental class II div 2, proper image quality, and clarity.

\section{Crown-Root Angle}

The crown-root angle was conventionally measured according to three points on the most forward maxillary central incisor: (1) the intact incisal edge (incisor superius [IS]), (2) the established bisection of the facial CEJ (fCEJ) and lingual CEJ (ICEJ), and (3) the anatomic root apex (upper incisor apical [UIA]). ${ }^{11}$ The crown-root angle is the supplement (180 degrees $-\mathrm{x}$ ) of this angle. A straight tooth was taken to have a crown-root angle of 0 , a lingually inclined root was taken to have a (+) angle, and a labially inclined root was taken to have a (-) angle. The crown-root angulation measurement, used in this study, is shown in - Fig. 1.

\section{Labial Crown-Root Angle}

The labial crown-root angle was built on a cephalometric radiograph with three points on the most forward maxillary

Table 1 Grouping of the sample

\begin{tabular}{|l|l|l|}
\hline Grouping & Malocclusion & Number of patients \\
\hline Group A & Class I & 15 \\
\hline Group B & Class II div 1 & 15 \\
\hline Group C & Class II div 2 & 15 \\
\hline
\end{tabular}



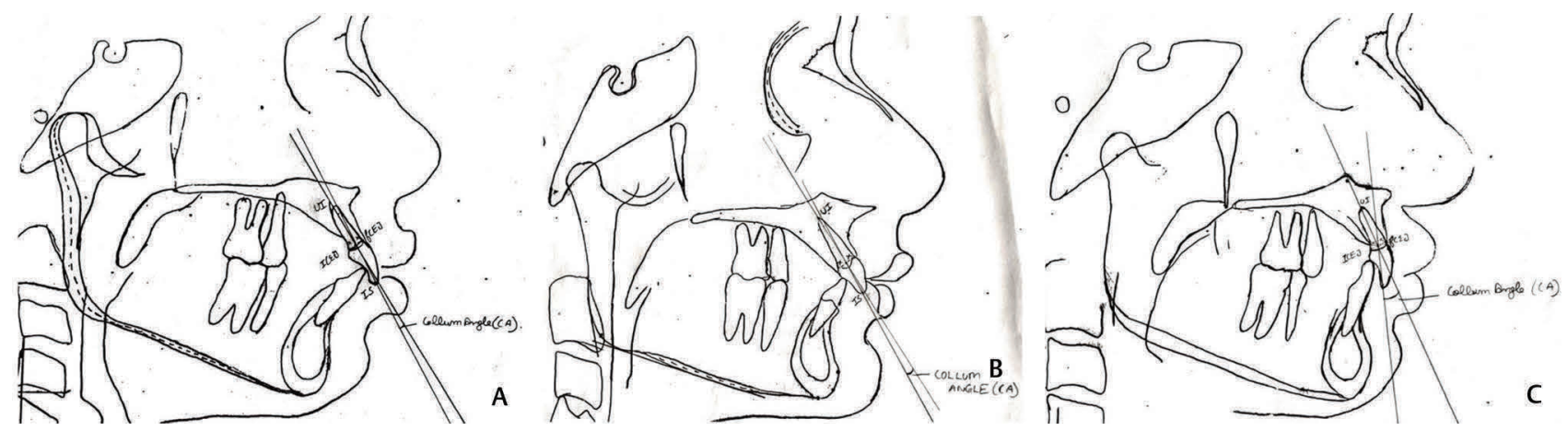

Fig. 1 (A) Crown-root angle in class I patients. (B) Crown-root angle in class II div 1 patients. (C) Crown-root angle in class II div 2 patients.
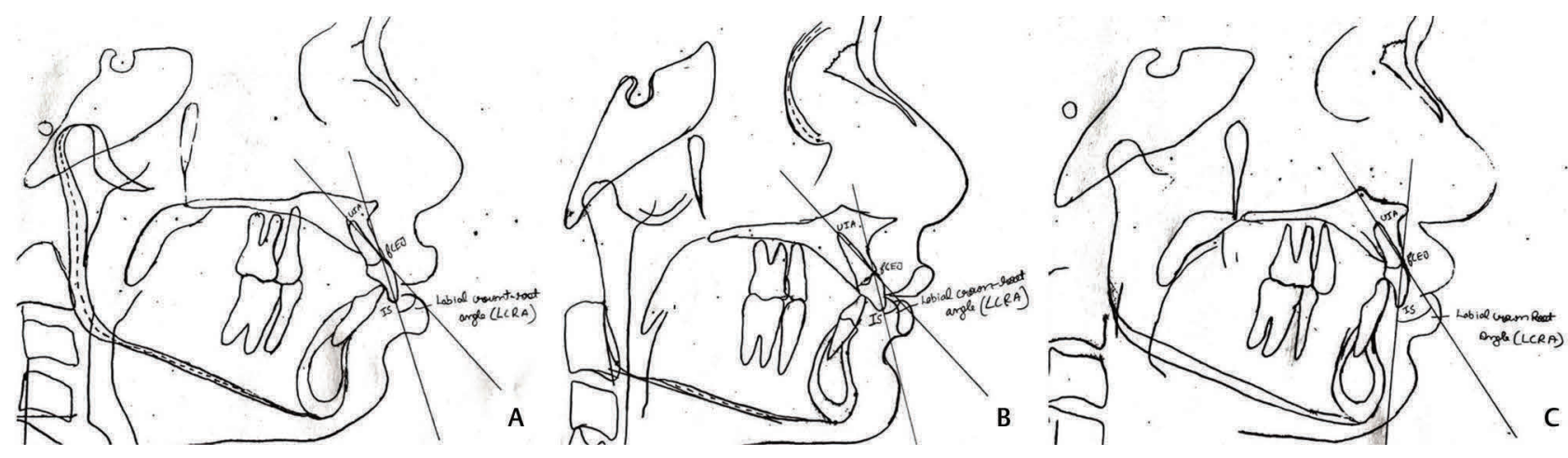

Fig. 2 (A) Labial crown-root angle in class I patients. (B) Labial crown-root angle in class II div 1 patients. (C) Labial crown-root angle in class II div 2 patients.

Table 2 Mean crown-root angle in three groups

\begin{tabular}{|l|l|l|l|l|}
\hline \multicolumn{5}{|l|}{ Descriptive } \\
\hline Crown-root angle \\
\hline Group & $\mathbf{N}$ & Mean & $\begin{array}{l}\text { Standard } \\
\text { deviation }\end{array}$ & $\begin{array}{l}\text { Standard } \\
\text { error }\end{array}$ \\
\hline A (class I) & 15 & 5.8000 & 6.55962 & 1.69369 \\
\hline B (class II div 1) & 15 & 5.3333 & 4.28730 & 1.10698 \\
\hline C (class II div 2) & 15 & 15.6000 & 9.69389 & 2.50295 \\
\hline Total & 45 & 8.9111 & 8.50621 & 1.26803 \\
\hline
\end{tabular}

central incisor: (1) IS, (2) fCEJs, and (3) UIA. The labial crownroot angle is the supplement (180 degrees $-\mathrm{x}$ ) of this angle. The labial crown-root angle is illustrated in - Fig. 2.

The measurement for these two parameters that is crownroot and labial crown-root angles was completed on all the 45 patients of three groups. The data so obtained were collected and analyzed statistically.

\section{Statistical Methods}

The statistical analysis was done using IBM SPSS (Statistical Package for Social Sciences, Armonk, New York, United States) statistical version 20. Normality of data was checked by Kolmogorov-Smirnov tests of normality. All quantitative variables were assessed using measures of central location (mean) and measures of dispersion (standard deviation). For normally distributed data, the comparison of crown-root and labial crown-root angles among various groups was made by comparing the means using one-way analysis of variance (ANOVA) (for more the two groups) with post hoc. Multiple comparisons were made using Scheffe test. For correlation of two parameters, Pearson's correlation was used for data normally distributed. Altogether statistical tests were seen at two-tailed level of significance ( $p \leq 0.01$ and $p \leq 0.05)$.

\section{Explanation of Pearson's Correlation Coefficient \pm 0.0 No correlation \\ \pm 0.2 Weak \\ \pm 0.5 Moderate \\ \pm 0.8 Strong \\ \pm 1.0 Perfect}

\section{Results}

\section{Mean Crown-Root Angle}

This study compared the crown-root angle in various malocclusions. The mean value of crown-root angle was found to be highest in group $\mathrm{C}$, that is, class II div 2 group, that is, $15.6 \pm 9.69$ degrees. This was followed by the crown-root angle of group $A$, that is, $5.8 \pm 6.5$ degrees and then crown-root angle of group B, that is, $5.3 \pm 4.2$ degrees (-Table 2, - Fig. $\mathbf{3}$ ).

\section{Comparison of Three Groups for Measurement of Crown-Root Angle}

On comparison of crown-root angle of different malocclusion groups, no significant difference was found between groups $\mathrm{A}$ and $B$ whereas there was a statistically significant difference between groups $B$ and $C$ with a $p=0.001$. A statistically significant difference was also found between groups $A$ and C with a $p=0.002$ (-Table 3 ). 


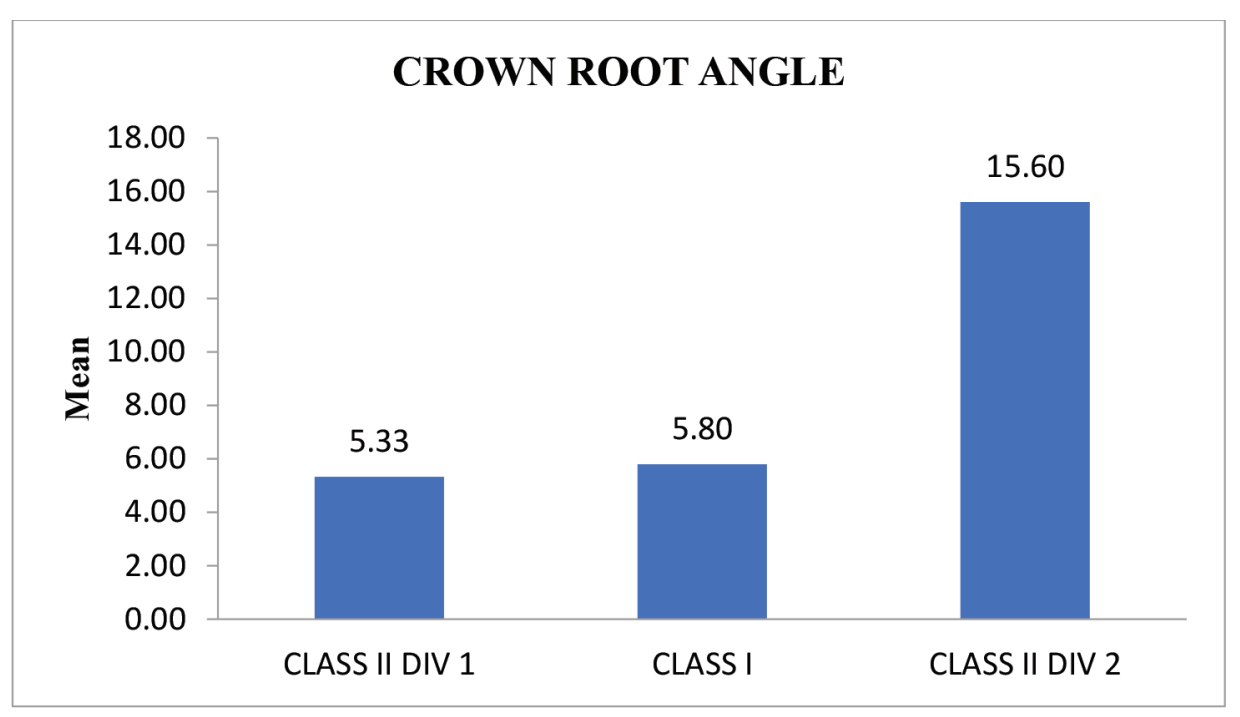

Fig. 3 Mean crown-root angle in three groups.

Table 3 Comparison of crown-root angle in three groups

\begin{tabular}{|l|l|l|l|l|}
\hline Group & Group & Mean difference & Standard error & p-Value \\
\hline A (class I) & B (class II div 1) & -0.46667 & 2.62789 & 0.984 \\
\hline B (class II div 1) & C (class II div 2) & -10.26667 & 2.62789 & $0.001^{* *}$ \\
\hline C (class II div 2) & A (class I) & -9.80000 & 2.62789 & $0.002^{* *}$ \\
\hline
\end{tabular}

${ }^{* *} p$-value is less than 0.01 .

\section{Mean Labial Crown-Root Angle}

The mean labial crown-root angle was compared for various groups. The mean crown-root angle for group $\mathrm{C}$, that is, class II div 2 group was found to be highest, that is, $39.8 \pm 9.8$ degrees. This was followed by labial crown-root angle of $28.8 \pm$ 5.8 degrees for group A and then labial crown-root angle of $27.06 \pm 4.9$ degrees for group B. Mean labial crown-root angle for group A was 28.8667 degrees. Mean labial crown-root angle for group B was 27.0667 degrees. Mean crown-root angle for group C was 39.8000 degrees ( - Table 4, - Fig. 4).

\section{Comparison of Three Groups for Labial Crown-Root Angle}

When labial crown-root angle for the three groups was compared, no significant difference was found between groups A and $B$ whereas a statistically significant difference was found between groups B and C with a $p=0.0001$.

A statistically significant difference was also found between groups A and C with a $p=0.001$ (-Table 5).

\section{Correlation between Crown-Root and Labial Crown-Root Angles}

The crown-root and labial crown-root angles were evaluated for correlation in all the three groups. A strong correlation was found for both the angles in all the three groups with a Pearson's correlation coefficient of $0.939^{* *}$ (**indicates $p<0.01$ ).

There was significant correlation between crown-root and labial crown-root angles in combined values for all the three groups, as shown in - Table 6.

There was a significant correlation between the crownroot and labial crown-root angles with groups A, B, and C, as shown in - Tables 7 to $\mathbf{9}$, respectively.
Table 4 For mean labial crown-root angle in three groups

\begin{tabular}{|l|l|l|l|l|}
\hline \multicolumn{5}{|l|}{ Descriptive } \\
\hline Labial crown-root angle (LCRA) \\
\hline Group & $N$ & Mean & $\begin{array}{l}\text { Standard } \\
\text { deviation }\end{array}$ & $\begin{array}{l}\text { Standard } \\
\text { error }\end{array}$ \\
\hline A (class I) & 15 & 28.8667 & 5.80476 & 1.49878 \\
\hline B (class II div 1) & 15 & 27.0667 & 4.94927 & 1.27790 \\
\hline C (class II div 2) & 15 & 39.8000 & 9.85031 & 2.54334 \\
\hline Total & 45 & 31.9111 & 9.04238 & 1.34796 \\
\hline
\end{tabular}

Table 5 Comparison of labial crown-root angle in three groups

\begin{tabular}{|l|l|l|l|l|}
\hline Group & Group & $\begin{array}{l}\text { Mean } \\
\text { difference }\end{array}$ & $\begin{array}{l}\text { Standard } \\
\text { error }\end{array}$ & $\boldsymbol{p}$-Value \\
\hline A (class I) & B & -1.8000 & 2.62652 & 0.792 \\
\hline $\begin{array}{l}\text { B (class II } \\
\text { div 1) }\end{array}$ & C & -12.73333 & 2.62652 & $0.0001^{* *}$ \\
\hline $\begin{array}{l}\text { C (class II } \\
\text { div 2 }\end{array}$ & A & -10.93333 & 2.62652 & $0.001^{* *}$ \\
\hline
\end{tabular}

${ }^{* *} p$-value is less than 0.01 .

\section{Discussion}

The variability of tooth morphology has been reported in the literature for all the malocclusion. The tooth morphology varies in crown shape and size, root shape and size, and their relation to each other. Since the advent of cephalometry and its use in orthodontics, the angulation of the central incisors has been evaluated and studied. The relationship of the 


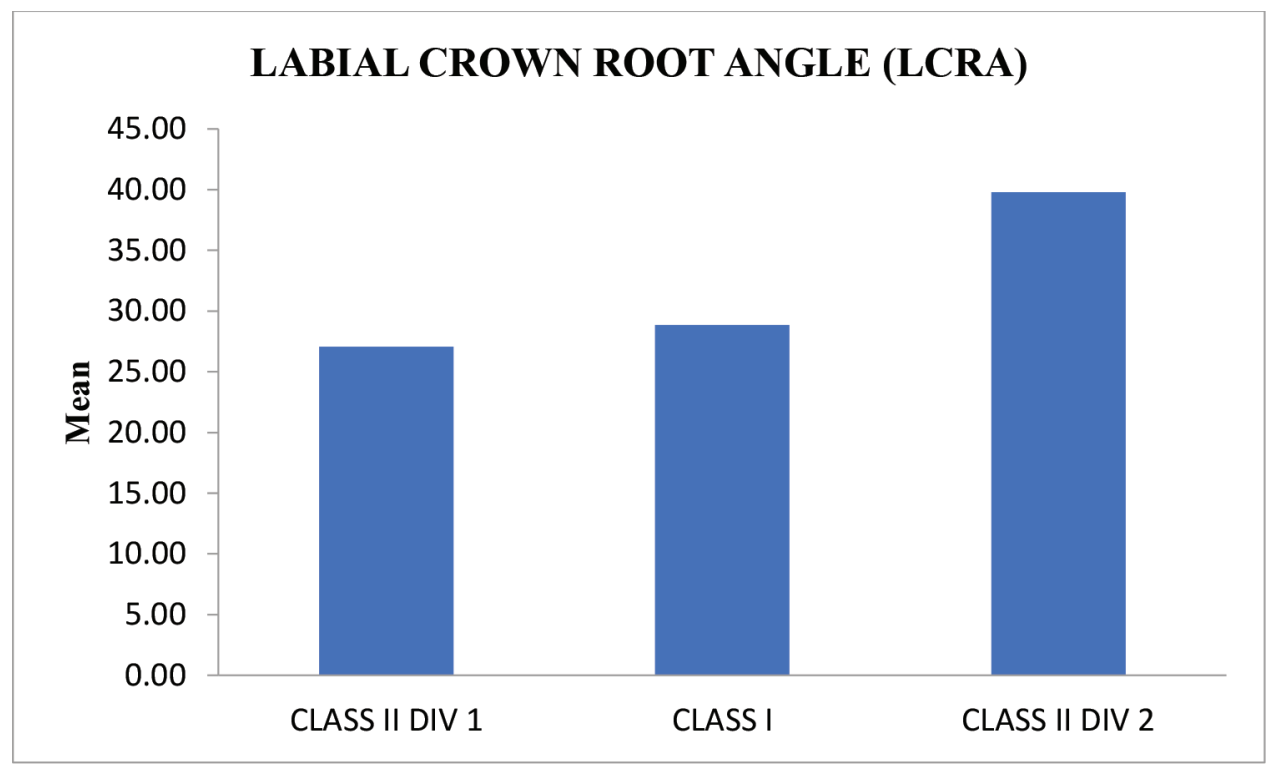

Fig. 4 For mean labial crown-root angle in three groups. $\mathrm{Cl}$, confidence interval.

Table 6 Correlation between labial crown-root and crownroot angles in all three groups

\begin{tabular}{|l|l|l|l|}
\hline \multicolumn{2}{|l|}{ Correlations } & $\begin{array}{l}\text { Collum angle } \\
\text { (CA) }\end{array}$ & $\begin{array}{l}\text { Labial crown-root } \\
\text { angle (LCRA) }\end{array}$ \\
\hline \multirow{2}{|c|}{$\begin{array}{l}\text { Crown- } \\
\text { root } \\
\text { angle }\end{array}$} & $\begin{array}{l}\text { Pearson's } \\
\text { correlation }\end{array}$ & 1 & $0.939^{* *}$ \\
\cline { 2 - 4 } & $p$-Value & & 0.000 \\
\cline { 2 - 4 } & $N$ & 45 & 45 \\
\hline \multirow{2}{*}{$\begin{array}{l}\text { Labial } \\
\text { crown- } \\
\text { root } \\
\text { angle }\end{array}$} & $\begin{array}{l}\text { Pearson's } \\
\text { correlation }\end{array}$ & $0.939^{* *}$ & 1 \\
\cline { 2 - 4 } & $p$-Value & 0.000 & 45 \\
\cline { 2 - 4 } & $N$ & 45 & \\
\hline
\end{tabular}

${ }^{* *} p$-value is less than 0.01 .

Table 7 Correlation between labial crown-root and crownroot angles in group $\mathrm{A}$

\begin{tabular}{|l|l|l|l|}
\hline \multicolumn{2}{|l|}{ Correlations } & $\begin{array}{l}\text { Collum } \\
\text { angle (CA) }\end{array}$ & $\begin{array}{l}\text { Labial crown-root } \\
\text { angle (LCRA) }\end{array}$ \\
\hline $\begin{array}{l}\text { Crown- } \\
\text { root } \\
\text { angle }\end{array}$ & $\begin{array}{l}\text { Pearson's } \\
\text { correlation }\end{array}$ & 1 & $0.828^{* *}$ \\
\cline { 2 - 4 } & $p$-Value & & 0.0001 \\
\cline { 2 - 4 } & $N$ & 15 & 15 \\
\hline \multirow{2}{*}{$\begin{array}{l}\text { Labial } \\
\text { crown- } \\
\text { root } \\
\text { angle }\end{array}$} & $\begin{array}{l}\text { Pearson's } \\
\text { correlation }\end{array}$ & $0.828^{* *}$ & 1 \\
\cline { 2 - 4 } & $p$-Value & 0.0001 & 15 \\
\cline { 2 - 4 } & $N$ & 15 & \\
\hline
\end{tabular}

${ }^{* *} p$-value is less than 0.01 .

upper central incisors to the surrounding structures in all the planes of space is very important for the purpose of diagnosis and treatment planning. It has been assumed for all clinical
Table 8 Correlation between labial crown-root and crownroot angles in group B

\begin{tabular}{|c|c|c|c|}
\hline \multicolumn{4}{|c|}{ Correlations } \\
\hline & & $\begin{array}{l}\text { Collum } \\
\text { angle (CA) }\end{array}$ & $\begin{array}{l}\text { Labial crown-root } \\
\text { angle (LCRA) }\end{array}$ \\
\hline \multirow{3}{*}{$\begin{array}{l}\text { Crown- } \\
\text { root } \\
\text { angle }\end{array}$} & $\begin{array}{l}\text { Pearson's } \\
\text { correlation }\end{array}$ & 1 & $0.867^{* *}$ \\
\hline & $p$-Value & & 0.0001 \\
\hline & $N$ & 15 & 15 \\
\hline \multirow{3}{*}{$\begin{array}{l}\text { Labial } \\
\text { crown- } \\
\text { root } \\
\text { angle }\end{array}$} & $\begin{array}{l}\text { Pearson's } \\
\text { correlation }\end{array}$ & $0.867^{* *}$ & 1 \\
\hline & $p$-Value & 0.0001 & \\
\hline & $N$ & 15 & 15 \\
\hline
\end{tabular}

${ }^{* *} p$-value is less than 0.01 .

and cephalometric purposes that the long axis of the crown and root of the central incisors coincides.

This idea has been perpetrated further by the Andrews straight-wire appliance. When Dr. Andrews designed the first fully programmable brackets, he revolutionized the field of orthodontics. This development was based on the six keys of normal occlusion, wherein he named crown inclination as the third key. ${ }^{12}$ Although the importance of crown inclination was widely discussed, no mention of the crown in relation to the root was made in the "six keys of normal occlusion." 12 This omission may have subsequently propagated the assumption that the longitudinal axis of crown and root formed a straight line. ${ }^{9}$ The aforementioned concept is especially apparent in cephalometric analyses in which the crown to root angulation is not evident in the maxillary incisor templates. ${ }^{13}$ Instead, the maxillary incisor template is automatically drawn in, such that the long axes of the crown and root are identical. By doing so, crown inclination is taken into consideration, but no forethought is given to the inclination of the root and its inherent consequences. 
Table 9 Correlation between labial crown-root and crownroot angles in group $C$

\begin{tabular}{|l|l|l|l|}
\hline \multicolumn{2}{|l|}{ Correlations } & $\begin{array}{l}\text { Collum } \\
\text { angle (CA) }\end{array}$ & $\begin{array}{l}\text { Labial crown-root } \\
\text { angle (LCRA) }\end{array}$ \\
\hline \multirow{2}{|c|}{$\begin{array}{l}\text { Crown- } \\
\text { root } \\
\text { angle }\end{array}$} & $\begin{array}{l}\text { Pearson's } \\
\text { correlation }\end{array}$ & 1 & $0.962^{* *}$ \\
\cline { 2 - 4 } & $p$-Value & & 0.0001 \\
\cline { 2 - 4 } & $N$ & 15 & 15 \\
\hline \multirow{2}{*}{$\begin{array}{l}\text { Labial } \\
\text { crown- } \\
\text { root } \\
\text { angle }\end{array}$} & $\begin{array}{l}\text { Pearson's } \\
\text { correlation }\end{array}$ & $0.962^{* *}$ & 1 \\
\cline { 2 - 4 } & $p$-Value & 0.0001 & 15 \\
\cline { 2 - 4 } & $N$ & 15 & \\
\hline
\end{tabular}

${ }^{* *} p$-value is less than 0.01 .

All treatment approaches in the various techniques are based on the assumption, but over time, various authors have found this notion to be incorrect. It is frequently found that in the long axis of crown and root does not coincide and treatment mechanics based on this assumption can lead to root apices coming in contact with the bone.

The crown-root angle is evaluated by drawing a line from incisal edge, point bisecting the fCEJ and ICEJ and anatomic root apex.

In some cases, it may not be possible to accurately locate the midpoint of the CEJ, so a point on the labial surface of the CEJ was proposed by Bauer (2014). ${ }^{10}$ The advantage of the point was easy location by different observers. The aim of this study was to correlate this point with the crown-root angle to ascertain whether this point can be used routinely for the purpose of checking the angulation between the crown and root.

\section{Correlation between Crown-Root and Labial Crown-Root Angles}

A significant correlation was found between crown-root and labial crown-root angles in all the groups in this study, thus validating the use of labial crown-root angle with crown-root angle. This trend is similar to that reported by Bryant and colleagues (1984) ${ }^{13}$ and Bauer (2014). ${ }^{10}$

\section{Comparing Groups A (Class I) and B (Class II Div 1)}

In this study, mean value for groups $A$ and $B$ shows no significant difference regarding the collum angle (- Table 3 ). It goes same with the mean value for labial crown-root angle (-Table 5). The results presented a trend that is parallel to trends reported by other researchers such as Delivanis (1980), ${ }^{5}$ Bryant and colleagues (1984), ${ }^{13}$ Williams and Woodhouse (1983), ${ }^{14}$ Shen and colleagues (2012), ${ }^{15}$ and Shailaja and colleagues (2016). ${ }^{16}$

Comparing Groups B (Class II Div 1) and C (Class II Div 2) This study shows a significant difference between mean values for crown-root angle in groups B and C (-Table 3 ). Also, for the labial crown-root angle, both the groups show significant difference in mean values (-Table $\mathbf{5}$ ). The results showed a trend ( - Table 2 ). Similar results have been reported by other researchers such as Delivanis (1980), ${ }^{5}$ Bryant and colleagues (1984), ${ }^{13}$ Williams and Woodhouse (1983), ${ }^{14}$ Shen and colleagues (2012), ${ }^{15}$ Shailaja and colleagues (2016). ${ }^{16}$

\section{Comparing Groups C (Class II Div 2) and A (Class I)}

Both the groups show significant difference in mean values for crown-root angle (-Table 3 ). The same follows for the mean values for the labial crown-root angle (-Table 5). The results showed a trend ( $\mathbf{- T a b l e ~} \mathbf{2}$ ) parallel to trends reported by other researchers such as Delivanis (1980), ${ }^{5}$ Bryant and colleagues (1984), ${ }^{13}$ Williams and Woodhouse (1983), ${ }^{14}$ Shen and colleagues (2012), ${ }^{15}$ Shailaja and colleagues (2016). ${ }^{16}$

Thus, it can be said that an accurate evaluation of the angulation of crown and root axis is crucial for the determination of diagnosis and treatment planning. The crown-root and labial crown-root angulations should be evaluated and taken into consideration when planning for the central incisors and anterior segment.

\section{Conclusions}

- Class II div 2 malocclusion group has greater crown-root and labial crown-root angles than class II div 1 and class I malocclusion.

- Class I malocclusion and class II div 1 have similar crownroot angle and labial crown-root angle values.

- Crown-root and labial crown-root angles are strongly correlated in all the three malocclusions: class I, class II div 1 , and class II div 2.

\section{Conflict of Interest}

None declared.

\section{References}

1 Mavroskoufis F, Ritchie GM. Variation in size and form between left and right maxillary central incisor teeth. J Prosthet Dent 1980;43(3):254-257

2 Salzmann J. The face in profile; an anthropological X-ray investigation on Swedish children and conscripts. Am J Orthod 1948;34(8):691-699

3 Andreasen V. Fine Systematische Gnathophysiognometrische Diagnose. Nor Tannlaegeforen Tid 1930;40:167

4 Taylor RM. Variation in form of human teeth: I. An anthropologic and forensic study of maxillary incisors. J Dent Res 1969;48(1):5-16

5 Delivanis HP, Kuftinec MM. Variation in morphology of the maxillary central incisors found in class II, division 2 malocclusions. Am J Orthod 1980;78(4):438-443

6 Backlund E. Tooth form and overbite. Trans Eur Orthod Soc 1960;36:97-104

7 Carlsson R, Rönnerman A. Crown-root angles of upper central incisors. Am J Orthod 1973;64(2):147-154

8 Andrews LF, Schirmer L. Straight Wire. San Diego, CA: L.A. Wells Co.; 1989

9 Harris EF, Hassankiadeh S, Harris JT. Maxillary incisor crownroot relationships in different angle malocclusions. Am J Orthod Dentofacial Orthop 1993;103(1):48-53

10 Bauer TJ. Maxillary central incisor crown-root relationships in class I normal occlusions and class II division 2 malocclusions, 2014 
11 Rakosi T. An Atlas and Manual of Cephalometric Radiography. Philadelphia, PA: Lea \& Febiger; 1982

12 Andrews LF. The six keys to normal occlusion. Am J Orthod 1972;62(3):296-309

13 Bryant RM, Sadowsky PL, Hazelrig JB. Variability in three morphologic features of the permanent maxillary central incisor. Am J Orthod 1984;86(1):25-32

14 Williams A, Woodhouse C. The crown to root angle of maxillary central incisors in different incisal classes. $\mathrm{Br} \mathrm{J}$ Orthod 1983;10(3):159-161
15 Shen Y, Hsu J, Wang Y, Huang H, Fuh L. The collum angle of the maxillary central incisors in patients with different types of malocclusion. J Dent Sci 2012;7:72-76

16 Shailaja AM, Gowda CN, Gowda S. The collum angle of maxillary central incisors in different skeletal malocclusions-a cephalometric study. Int J Applied Dental Sci 2016;2(3):33-36 